\title{
Utilization of Date-pits in Transformer Oil Chemical Regeneration
}

\author{
Sulaiman Al-Zuhair \\ Chemical Engineering \\ UAE University \\ Al-Ain, UAE
}

\author{
Hassan Noura \\ Electrical Engineering \\ UAE University \\ Al-Ain, UAE
}

\author{
Abbas Fardoun \\ Electrical Engineering \\ UAE University \\ Al-Ain, UAE
}

\begin{abstract}
High quality transformer oil is required to increase the reliability and the life time of the transformer. This oil carries information about the operating condition of the transformer. Therefore, the transformer oil properties should be monitored in order to give early warnings and maintain the transformers efficiency. When the oil quality is decreased, it should be either changed or regenerated. Transformer oil regeneration was carried out using adsorption on Activated Carbon (AC) produced from waste date-pits. After adsorption, drop in density, viscosity, neutralization index and metallic contents were observed, whereas adsorption resulted in an increase in interfacial tension. The properties of the regenerated oil after adsorption was found to approach the acceptable standards, which clearly demonstrate the potential of using locally made AC from waste date-pits as an adsorption agent for transformer oil regeneration.
\end{abstract}

\section{Introduction}

Oils, which are essentially electrical insulators, are used in electrical power transformers, mainly to transfer the heat and to increase the dielectric strength of the insulating paper [1,2]. However, ageing, dust and metal particles, as well as humidity, deteriorate the isolating and cooling properties of the transformer oil, which increase the risk on equipment and operators. Degradation of transformer insulation, which in part defines the life span of a transformer, is monitored by sampling the transformer oil $[3,4]$. Therefore, oil test should be scheduled regularly in order to determine its breakdown voltage. This test helps to increase the lifetime of the transformers and therefore, new investment to replace these transformers could be delayed. The transformer oil test is mandatory in some countries. Thermal, electrical, physical and chemical characteristics of the transformer oil are typically tested. Figure 1 shows a cutaway of a single phase transformer including the resvoir for the oil. One main electrical test is the breakdown voltage test. As the oil quality becomes poorer, its breakdown voltage decreases.

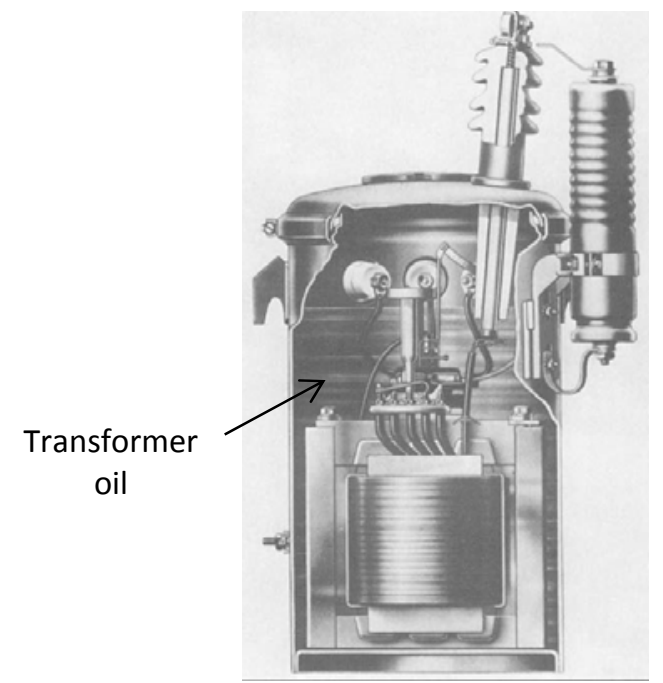

Figure 1. Transformer cutaway [1]

In order to increase the equipment lifetime, oils are usually replaced with fresh ones at regular basis, which is not a cost effective solution. Both environmental and economical reasons prevent discarding the spent oils, after use. The used oils contain a large proportion of valuable base oil that may be reused, if undesirable pollutants are removed. This is to say that transformer oil can be regenerated and its original specifications can be restored.

The regeneration of the transformer oil is a green technology and could be done in continuous operation and is decomposed into different steps:

- Heat and filtration

- Adsorption process

- Fine filtration

- Degasification and dehydration

If oil is regenerated properly, its main properties can be highly improved. Among these properties are the density, viscosity, interfacial tension, breakdown voltage, and neutralization value.

The main step in the regeneration of transformer oil is carried out using the adsorption process, which consists of the removal of the acid components, water and oxidation products with an adsorbent. Currently, activated bauxite is used as an adsorbent for the recovery of aged oil in order to regenerate the oil, maintaining the properties of new oil with low cost [5]. One of the problems of the regeneration process with bauxite is the great volume of waste that is discarded in landfill sites [6]. It is thus 
necessary to examine the effectiveness of other raw materials, especially from renewable sources, that possess adsorbent properties for removing impurities in the treatment of insulating oil without causing damage to the environment. Recently, an attempt has been made to utilize vacuum gas oil and spindle oil obtained from the vacuum distillation of paraffinic crude oil for transformer oil production [7]. This offers a cheaper alternative to conventional transformer oils; however, this technique does not address the hazardous environmental impact of the spent oil.

Many investigations have been done on the production of low cost adsorbents using cheaper and readily available materials. It has been reported that the use of carbonated amorphous calcium phosphate (CACP) microparticles as an alternative adsorbent to replace bauxite in the removal of polar compounds present in mineral oil previously used in transformers has shown impressive results [6]. Chitosan (CHS), a biopolymer found naturally in the exoskeletons of insects, crustaceous shells and fungal cell walls, is used to bind the adsorbent CACP microparticles together. This material showed a better performance than bauxite in relation to the color and interfacial tension (IT) of regenerated oil. In addition, the use of this material for removal of polar compounds from aged insulating mineral oil could offer an alternative solution to the environmental problems generated by the use of bauxite, given that the phosphorous and calcium from CACP, and the nitrogen and carbon from CHS, are constituents of fertilizers and could be disposed of in landfill sites.

On the other hand, the use of activated carbon (AC), as an adsorbent, has proven to be effective in a wide range of applications, including the removal of both organic and inorganic pollutants [8]. The versatility of high surface area, porous structure and surface adsorption capacity, which can be appropriately modified by physical and chemical treatments, is among the reasons for the use of such adsorbent. However, the cost of commercially available AC is relatively high [9], and therefore great attention has been focused on the production of low-cost AC of properties comparable to those of the commercially available. In order to achieve this target, agricultural waste was considered as a promising raw material for generating AC capable of removing various pollutants

Date-pits (DP) constitute approximately $10 \%$ of the total weight of dates $[8,10]$, making them the largest agricultural by-product in palm growing countries, including the UAE. Therefore, finding ways to use this agricultural by-product profitably will benefit date farmers substantially and offers a useful alternative for its disposal or current use as animal feed [10]. In addition to producing AC from inexpensive raw material, using (DP) is considered a waste minimization process.
DP-AC was previously prepared by physical [11, 12] and chemical activation [13]. The objective of the present work is to explore the viability of using DP-AC, locally prepared by physical activation, as an environmentally friendly alternative adsorbent in the regeneration of transformer oil.

\section{Materials and methods}

\subsection{Materials preparation}

All Aged oil was collected from a local power station, UAE with the characteristics shown in Table 1. It can be noticed that the density, viscosity and interfacial tension of the aged oil were already within the acceptable margin, whereas other chemical and physical properties were not.

\section{Table 1. Summary of the effect of adsorption on the different properties of regenerated transformer oil (15\% for $24 \mathrm{hrs)}$}

\begin{tabular}{|l|l|l|l|l|l|}
\hline Property & Max & Min & Typical & $\begin{array}{l}\text { Before } \\
\text { Ads. }\end{array}$ & $\begin{array}{l}\text { After } \\
\text { Ads. }\end{array}$ \\
\hline $\begin{array}{l}\text { Viscosity, 20 }{ }^{\circ} \mathrm{C} \\
\text { Viscosity, } 40^{\circ} \mathrm{C} \\
\left(\mathrm{mm}^{2} / \mathrm{s}\right)\end{array}$ & 25.0 & 11.0 & $\begin{array}{l}17.1 \\
8.0\end{array}$ & $\begin{array}{l}20.1 \\
9.0\end{array}$ & $\begin{array}{l}17.7 \\
8.6\end{array}$ \\
\hline $\begin{array}{l}\text { Density, 20 } \mathrm{C} \\
\left(\mathrm{kg} / \mathrm{m}^{3}\right)\end{array}$ & 895 & & 882 & 871 & 870 \\
\hline $\begin{array}{l}\text { Neutralization } \\
\text { value (mg/g) }\end{array}$ & 0.03 & & 0.01 & 0.12 & 0.04 \\
\hline $\begin{array}{l}\text { Elemental } \\
\text { Sulfur (wt\%) }\end{array}$ & & & & 0.177 & 0.166 \\
\hline $\begin{array}{l}\text { Interfacial } \\
\text { tension (mN/m) }\end{array}$ & & 40 & 44 & 51 & 55 \\
\hline $\begin{array}{l}\text { Breakdown } \\
\text { Voltage (kV) }\end{array}$ & & 30 & $40-60$ & 20 & 30 \\
\hline
\end{tabular}

DP-AC was prepared from raw DP granules, obtained from Al-Saad Date Processing Factory, AlAin, UAE. The granules were washed, dried, grinded and screened. The collected granules were carbonated and activated to produce DP-AC. The carbonization is performed in a tube furnace (Thermolyene, USA) which has been initially purged with a flow of nitrogen for 10 minutes. After that, the furnace was heated at a rate of $10^{\circ} \mathrm{C} / \mathrm{min}$ up to 600 ${ }^{\circ} \mathrm{C}$ and then kept at this temperature for 4 hours. After cooling to room temperature, the material is considered carbonized, but still inactive. After weighing the inactive carbon, it was activated in the same tube furnace at a temperature of $900{ }^{\circ} \mathrm{C}$ using a flow of carbon dioxide instead of nitrogen. The resulting AC was then degassed under vacuum (Shel Lab, USA) for about 2 hours before use. The main surface characteristics of the prepared DP-AC were determined using a surface area analyzer (Micromeritics, Model ASAP-2010) and presented in Table 2. 
Table 2. Surface characteristics of prepared datepit activated carbon (DP-AC)

\begin{tabular}{|l|l|}
\hline Particle size $(\mu \mathrm{m})$ & $125-212$ \\
\hline BET surface area $\left(\mathrm{m}^{2} / \mathrm{g}\right)$ & 490 \\
\hline $\begin{array}{l}\text { BET surface area in the micropore } \\
\text { region }\left(\mathrm{m}^{2} / \mathrm{g}\right)\end{array}$ & 423 \\
\hline Total pore volume $\left(\mathrm{cm}^{3} / \mathrm{kg}\right)$ & 229 \\
\hline $\begin{array}{l}\text { Total pore volume in the micropore } \\
\text { region }\left(\mathrm{cm}^{3} / \mathrm{kg}\right)\end{array}$ & 165 \\
\hline
\end{tabular}

\subsection{Batch adsorption}

Batch adsorption experiment was carried out by contacting a specified amount of adsorbent with 50 $\mathrm{ml}$ waste oil sample, in a sealed glass bottle. The bottle was kept on a shaker (WSB-30, Korea) at different temperatures for 24 hours. The mixture was then vacuum-filtered (Shel Lab, USA) before sending for analysis.

\subsection{Oil analysis}

The physical and chemical properties of the aged and regenerated oil were analyzed. Physical properties tested included interfacial tension (Torsion Balance, White Elec. Inst. Co., USA), density and viscosity (Stabinger Viscometer - SVM300, Anton Paar, Austria). Chemical properties tested should include the metallic and phosphorous contents and neutralization number. The metallic content was measured using atomic absorption spectroscopy (Varion AA880, USA). Prior to the analyses the samples are heated at $200{ }^{\circ} \mathrm{C}$ for $4 \mathrm{~h}$ and calcined at $650{ }^{\circ} \mathrm{C}$ overnight. The samples are further treated with hydrochloric acid, filtered and diluted with deionized water. The phosphorous content was measured by energy dispersive X-ray fluorescence spectroscopy (Sulfur-Meter RX-360 SH, Tanaka Scientific, Japan). The neutralization index was determined by titration and must be less than 0.01 $\mathrm{mg} \mathrm{KOH} / \mathrm{g}$ oil. Another important property of the regenerated oil is its Break-Down Voltage, which was measured using Foster OTS60, USA. The success of the regeneration is measured by comparing the values of the physical and chemical properties of the aged oil after treatment with those of new oil according to the International Electrotechnical Commission.

\section{Results and discussions}

The density and viscosity of the used oil were measured after 24 and 48 hrs contact with different amounts of DP-AC at 20 and $40{ }^{\circ} \mathrm{C}$, and the results are shown in Figs. 2 - 5.

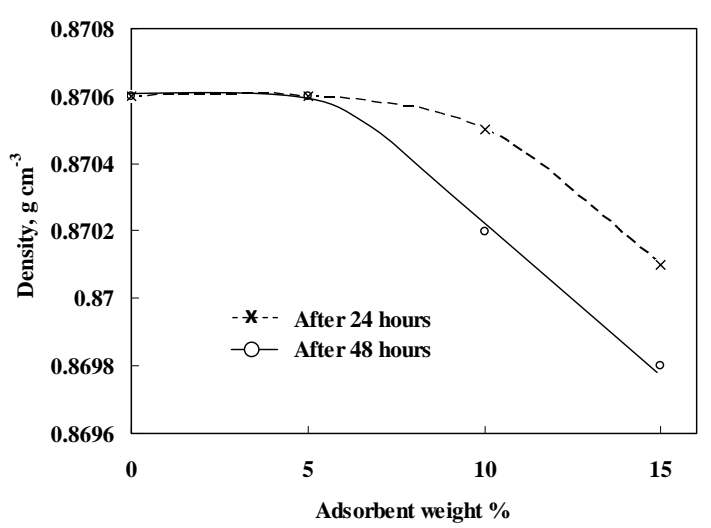

Figure 2. Drop in density at different adsorbent weights at $20^{\circ} \mathrm{C}$

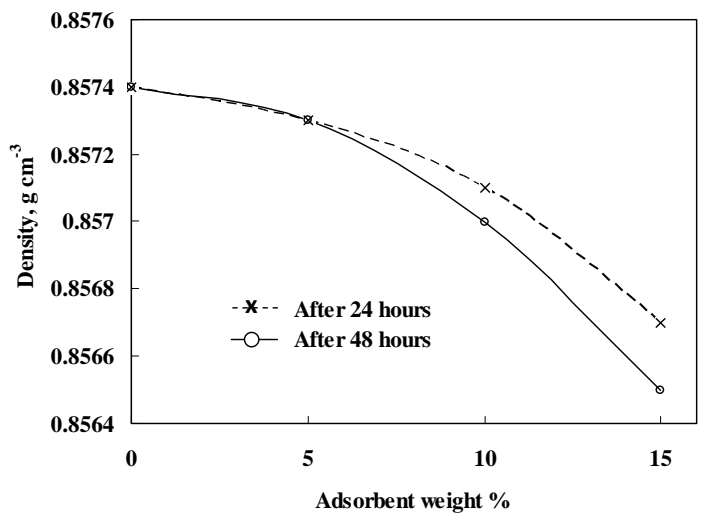

Figure 3. Drop in density at different adsorbent weights at $20^{\circ} \mathrm{C}$

The neutralization index was determined after 24 and 48 hrs contact with different amounts of DP-AC using titration against $\mathrm{KOH}$ and the results are shown in Fig. 6. It can be seen that the effect of the weight percentage of DP-AC was not significant, and the performance of $5 \mathrm{wt} \%$ were almost equivalent to higher amounts. This indicates that the impurities responsible for increasing the acid value can easily be adsorbed on DP-AC. It can also be observed that the effect of contact time is also negligible, due to the same reason. As shown in Fig. 6, the neutralization index dropped from 0.12 to $0.04 \mathrm{mg} \mathrm{g}$ 1 , which is slightly higher than the acceptable value of $0.03 \mathrm{mg} \mathrm{g}^{-1}$. The effectiveness of the DP-AC was less than that of CACP microparticles or Bauxide, which were able to drop the regenerated oil neutralization index to 0.005 and 0.007 , respectively [3]. 


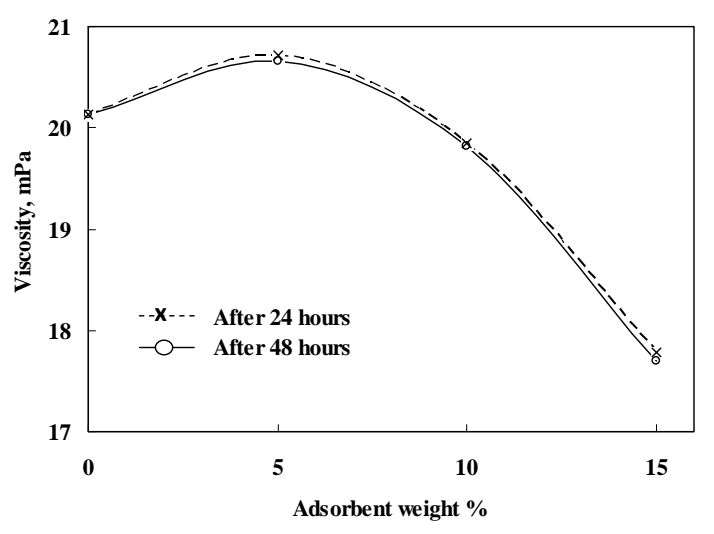

Figure 4. Drop in viscosity at different adsorbent weights at $20^{\circ} \mathrm{C}$

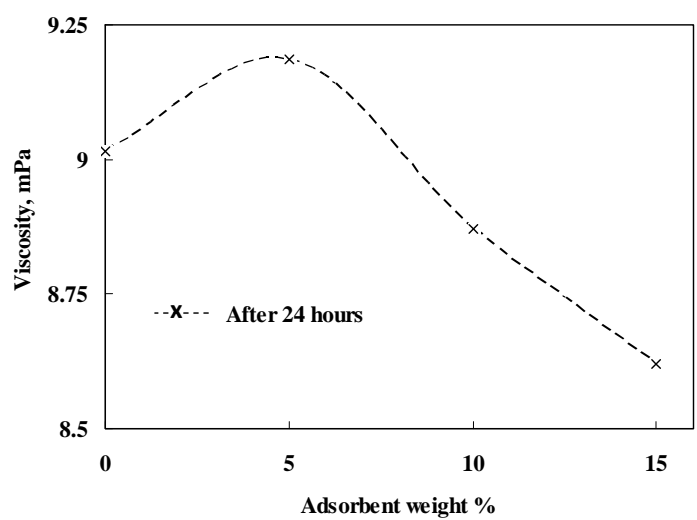

Figure 5. Drop in viscosity at different adsorbent weights at $40{ }^{\circ} \mathrm{C}$

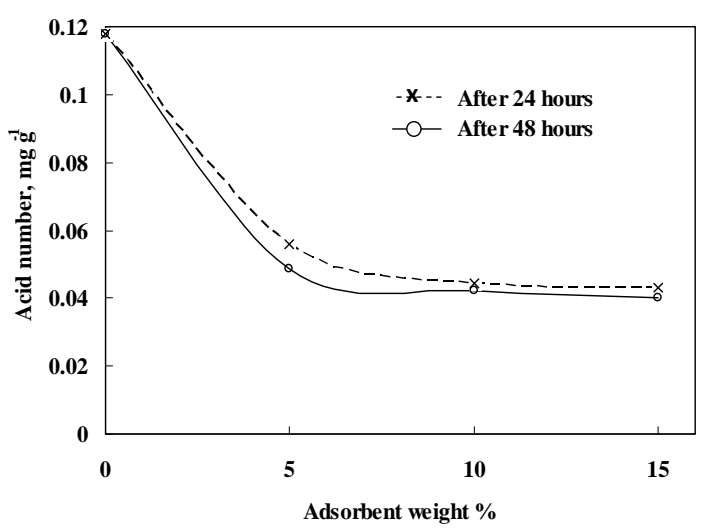

Figure 6. Drop in neutralization index at different adsorbent weights

Fig. 7 shows the variation in the interfacial tension as function of DP-AC weight percentage.

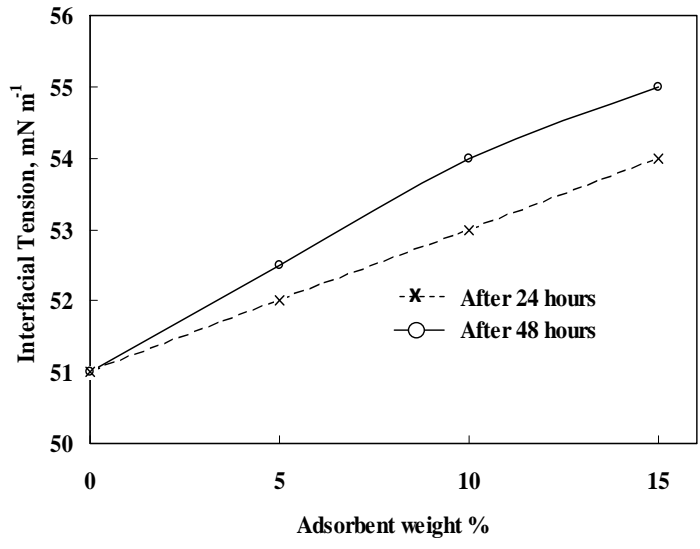

Figure 7. Increase in interfacial tension at different adsorbent weights

It is clearly seen that the interfacial tension increases almost linearly with the increase in the DPAC weight percentage. An increase by $7.8 \%$ was achieved using 15 wt $\%$ DP-AC 48 hrs of contact. The percentage increase was lower (4.9\%) for $24 \mathrm{hrs}$ contact. The increase in surface tension achieved using $\mathrm{AD}-\mathrm{CB}$ was much less than that reported by Laurentino et al. [6] using CACP microparticles. However, it should be noted that the interfacial tension of the aged oil used in this work was $51 \mathrm{mN}$ $\mathrm{m}^{-1}$, which is already much higher than the minimum acceptable $40 \mathrm{mN} \mathrm{m}^{-1}$, which renders the margin of improvement much less in this case, compared to the aged oil used by Laurentino et al. [6], which was initially $32 \mathrm{mN} \mathrm{m}^{-1}$. Above that, although the weight percentage of adsorbent was not mentioned in the work of Laurentino et al. [6], it is assumed to be much higher than those used in the work, as the description of their experiment suggests. In anyway, the results found in this work show the ability of the DP-AC to increase the interfacial tension.

Fig. 8 shows the percentage removal of different metal atoms after 24 hrs contact time with $15 \mathrm{wt} \%$ DP-AC.

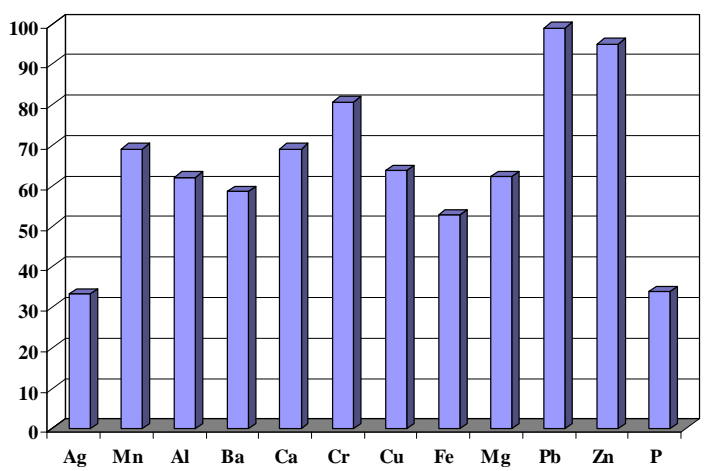

Figure 8. Percentage removal of metallic elements after 24 hours adsorption 
The DP-AC was found to be an excellent adsorbent, and complete removal was almost reached for $\mathrm{Pb}$ and $\mathrm{Zn}$. Although the removal of other elements was less, the removal percentage was always above $30 \%$.

One of the most important properties of transformer oil is its breakeven voltage, which is defined as the minimum applied voltage that would cause a given insulator to break down. According to the International Electrotechnical Commission standards, the breakeven voltage of the transformer oil should not be less than $30 \mathrm{kV}$. As shown in Table 1 , after contacting the aged oil with DP-AC for 24 hours, the breakeven voltage of the aged oil increased from 20 to $30 \mathrm{kV}$, which is a clear indication of the applicability of DP-AC as a regeneration adsorbent. Table 1 also shows comparison between other physical and chemical properties of the aged and regenerated oils compared to the standard values of the International Electrotechnical Commission. The results clearly show that the regenerated oil has acceptable levels of viscosity, density, interfacial tension and breakeven voltage. The only unacceptable value was the neutralization index, which the DP-AC although managed to decrease it by $66 \%$, yet did not reach the acceptable level, but approached it significantly though. The results found in this work show the ability of the DP-AC to be used as an absorbent for transformer oil regeneration.

\section{Conclusion}

Activated Carbon (AC) was produced from datepits, which is considered an agricultural waste, and used as an adsorbent in transformer oil regeneration. Measurement of the relevant physical and chemical properties of the aged oil before regeneration and those of the regenerated oil showed that the regenerated oil has acceptable levels of viscosity, density, interfacial tension and breakeven voltage, whereas the neutralization index although significantly approached the acceptable level, dropping by $68 \%$, it did not reach it. The results found in this work show the ability of the DP-AC to be used as an absorbent for transformer oil regeneration.

\section{References}

[1] A. F. Fitzgerald, C. Kingsley and S. Umans, "Electric Machinery”, $6^{\text {th }}$ edition, McGraw Hills.

[2] G.L. Goedde and A.P. Yerges (1998) 'Dielectric fluid for use in power distribution equipment', US patent 5,766,517. 1998.

[3] L. Nasrat, M. Abdelwahab and G. Ismail, "Improvement of Used Transformer Oils with Activated
Bentonite”, Journal of Engineering, Vol. 3, pp 588-593, 2011.

[4] R. Ferguson, A. Lobeiras and J. Sabau, "Suspended Particles in the Liquid Insulation of Power Transformers" IEEE Electrical Insulation Magazine, Vol. 18, No. 4, pp. 17-23, August 2002.

[5] A.A. Al-Zahrani and M.A. Daous (2000) 'Recycling of spent bleaching clay', Process Safety and Environment Protection (78-B3), pp. 224-228.

[6] A.C. Laurentino, A.L. Parize, M.C.M. Laranjeira, A.R. Martins, N.M. Mayer and V.T. De Fa'vere (2007) 'Regeneration of insulating Mineral Oil by Carbonated Amorphous Calcium Phosphate-Chitosan Adsorbent', Process Safety and Environment Protection (85-B4), pp. 327-331.

[7] M.S. El-Gayar, G.A. Gohar, A.M. Ibrahim, H.M. Ibrahim and A.M. Aly (2008) 'Transformer oils prepared from the vacuum distillates of Egyptian crude paraffinic petroleum'. Fuel Processing Technology (89), pp. 254-261.

[8] E. El-Sharkawy, A. Soliman and K. Al-Amer (2007) 'Comparative study for the removal of methylene blue via adsorption and photocatalytic degradation', Journal of Colloids and Interface Science (310), pp. 498-508.

[9] S. Babel and T.A. Kurniawan (2003) 'Low-cost adsorbents for heavy metals uptake from contaminated water: a review', Journal of Hazardous Materials, (97), pp. 219-243.

[10] J. Hamada, I. Hashim and F. Sharif (2002) 'Preliminary analysis and potential uses of date pits in foods', Food Chemistry (76), pp. 135-137.

[11] S. Al-Zuhair, A. Dowaidar and H. Kamal (2010) 'Inhibitory effect of dates-extract on $\alpha$-amylase and $\alpha$ glucosidase enzymes relevant to non-insulin dependent diabetes mellitus', Journal of Biochemical Technology, (2), pp. 158-160.

[12] M.H. El-Naas, S. Al-Zuhair and M. Abu AlHaija, 2010) 'Removal of phenol from petroleum refinery wastewater through adsorption on date-pit activated carbon', Chemical Engineering Journal, (162), pp. 9971005.

[13] F. Banat, S. Al-Asheh and L. Makhadmeh, (2003) 'Preparation and examination of activated carbons from date pits impergnated with potassium hydroxide for the removal of methylene blue from aqueous solutions', Adsorption Science and Technology, (21), pp. 597-606. 